\title{
Genetic Breast Cancer Susceptibility Variants and Prognosis in the Prospectively Randomized SUCCESS A Study
}

\section{Veranlagung für Brustkrebs: genetische Varianten und Prognose in der prospektiv randomisierten SUCCESS A-Studie}

\section{Authors}

A. Hein ${ }^{1}$, B. Rack ${ }^{\text {, }}$ L. Li ${ }^{3,4}$, A. B. Ekici ${ }^{5}$, A. Reis ${ }^{5}$, M. P. Lux ${ }^{1}$, J. M. Cunningham ${ }^{6}$, M. Rübner ${ }^{1}$, B. L. Fridley ${ }^{7,8}$, A. Schneeweiss ${ }^{9}$, H. Tesch $^{10}$, W. Lichtenegger ${ }^{11}$, T. Fehm ${ }^{12}$, G. Heinrich ${ }^{13}$, M. Rezai ${ }^{14}$, M. W. Beckmann ${ }^{1}$, W. Janni ${ }^{15}$, R. M. Weinshilboum ${ }^{3}$, L. Wang ${ }^{3}$,

P. A. Fasching ${ }^{1,16}$, L. Häberle ${ }^{1,17}$

\section{Affiliations}

1 Department of Gynecology and Obstetrics, Erlangen University Hospital, Friedrich-Alexander-University Erlangen-Nuremberg, Comprehensive Cancer Center Erlangen-EMN, Erlangen, Germany

2 Department of Gynecology and Obstetrics, LudwigMaximilians-University Munich, Munich, Germany

3 Division of Clinical Pharmacology, Department of Molecular Pharmacology and Experimental Therapeutics, Mayo Clinic College of Medicine, Mayo Medical SchoolMayo Foundation, Rochester, MN, USA

4 Department of Oncology; Institute of Medicinal Biotechnology; Chinese Academy of Medical Sciences \& Peking Union Medical College; Tiantan Xili, Beijing, 100050, China

5 Institute of Human Genetics, Erlangen University Hospital, Friedrich-Alexander-University ErlangenNuremberg, Erlangen, Germany

6 Department of Laboratory Medicine \& Pathology, Mayo Clinic, Rochester, MN, USA

7 Department of Health Sciences Research, Division of Biomedical Statistics and Informatics, Mayo Clinic, Rochester, MN, USA

8 Department of Biostatistics, University of Kansas Medical Center, Kansas City, KS, USA

9 Department of Gynecology and Obstetrics, University Hospital Heidelberg, National Center for Tumor Diseases, Heidelberg, Germany

10 Department of Oncology, Onkologie Bethanien, Frankfurt am Main, Germany

11 Department of Gynecology and Obstetrics, Charité University Hospital Campus Virchow, Berlin, Germany

12 Department of Gynecology and Obstetrics, University Hospital Duesseldorf, Heinrich-Heine University, Düsseldorf, Germany
13 Department of Gynecologic Oncology, Schwerpunktpraxis für Gynäkologische Onkologie, Fürstenwalde, Germany

14 Department of Breast Diseases, Breast Center of Düsseldorf, Luisenkrankenhaus, Düsseldorf, Germany

15 Department of Gynecology and Obstetrics, University Hospital Ulm, Ulm, Germany

16 Department of Medicine, Division of Hematology/ Oncology, University of California at Los Angeles, David Geffen School of Medicine, Los Angeles, CA, USA

17 Biostatistics Unit, Department of Gynecology and Obstetrics, Erlangen University Hospital, FriedrichAlexander-University Erlangen-Nuremberg, Erlangen, Germany

Schlüsselwörter

Brustkrebs, SNP, LSP1, Prognose, TNBC

Key words

breast cancer, SNP, LSP1, prognosis, TNBC

$\begin{array}{ll}\text { received } & 4.7 .2016 \\ \text { revised } & 21.7 .2016 \\ \text { accepted } & 22.7 .2016 \\ \text { updated by the authors } & 21.4 .2017 \\ \text { reaccepted } & 25.4 .2017\end{array}$

Bibliography

DOI http://dx.doi.org/10.1055/s-0042-113189

Geburtsh Frauenheilk 2017; 77: 651-659 @ Georg Thieme Verlag KG Stuttgart · New York | ISSN 0016-5751

\section{Correspondence}

Peter A. Fasching, MD

University Breast Center Franconia, Department of Gynecology and Obstetrics, Erlangen University Hospital, Friedrich Alexander University of Erlangen-Nuremberg, Comprehensive Cancer Center Erlangen-EMN Universitätsstraße 21-23, 91054 Erlangen, Germany peter.fasching@uk-erlangen.de

Supporting Information:

http://dx.doi.org/10.1055/s-0042-113189 


\section{ABSTRACT}

Large-scale genotyping studies have identified over 70 single nucleotide polymorphisms (SNPs) associated with breast cancer (BC) risk. However, knowledge regarding genetic risk factors associated with the prognosis is limited. The aim of this study was therefore to investigate the prognostic effect of nine known breast cancer risk SNPs. BC patients $(n=1687)$ randomly sampled in an adjuvant, randomized phase III trial (SUCCESS A study) were genotyped for nine BC risk SNPs: rs17468277(CASP8), rs2981582(FGFR2), rs13281615(8q24), rs3817198(LSP1), rs889312(MAP3K1), rs3803662(TOX3), rs13387042(2q35), rs4973768(SLC4A7), rs6504950(COX11). Cox proportional hazards models were used to test the SNPs' association with overall survival (OS) and progression-free survival (PFS). Additional analyses were carried out for molecular subgroups. rs3817198 in LSP1 (lymphocyte-specific protein 1) was the only SNP that significantly influenced OS $(p=0.01)$ and PFS $(p<0.01)$ in the likelihood ratio test comparing the genetic survival model with the clinical survival model. In the molecular subgroups, triple-negative patients with two minor alleles in rs3817198 had a much better prognosis relative to OS (adjusted HR 0.03; 95\% Cl 0.002-0.279) and PFS (HR 0.09; 95\% Cl 0.02-0.36) than patients with the common alleles. The same effect on PFS was shown for patients with luminal A tumors (HR 0.19; $95 \% \mathrm{Cl} 0.05-0.84$ ), whereas patients with luminal $\mathrm{B}$ tumors had a poorer PFS with two minor alleles (HR 2.13; 95\% Cl 1.02-4.40). The variant in rs3817198 has a prognostic effect particularly in the subgroup of patients with triple-negative BC, suggesting a possible link with immunomodulation and BC.

\section{ZUSAMMENFASSUNG}

In verschiedenen großangelegten Studien, in denen umfangreiche Genotypisierungsstudien vorgenommen wurden, wurden bislang über 70 Einzelnukleotid-Polymorphismen (SNPs) identifiziert, die mit einem erhöhten Brustkrebsrisiko einher- gehen. Aber das Wissen über die mit der Prognose assoziierten Risikofaktoren wächst weniger schnell. Ziel dieser Studie war es daher, die Auswirkungen von 9 bekannten Brustkrebsrisiko-SNPs auf die Prognose zu untersuchen. In einer adjuvanten randomisierten Phase-III-Studie (SUCCESS A-Studie) wurden Brustkrebspatientinnen ( $n=1687$ ) einer Genotypisierung unterzogen. Die Patientinnen waren zuvor nach dem Zufallsprinzip ausgewählt worden. Bei der Genotypisierung standen 9 Brustkrebsrisiko-SNPs im Mittelpunkt: rs17468277(CASP8), rs2981582(FGFR2), rs13281615(8q24), rs3817198(LSP1), rs889312(MAP3K1), rs3803662(TOX3), rs13387042(2q35), rs4973768(SLC4A7), rs6504950(COX11). Zur Überprüfung des Zusammenhangs zwischen SNP und Gesamtüberleben (OS) bzw. progressionsfreiem Überleben (PFS) wurde eine Cox-Regressionsanalyse durchgeführt. Molekulare Untergruppen wurden einer weiteren Analyse unterzogen. rs3817198 in LSP1 (Lymphozyten-spezifisches Protein 1) war der einzige SNP, für den im Likelihood-Ratio-Test, der das genetische Überlebensmodell mit dem klinischen Überlebensmodell verglich, eine signifikante Auswirkung auf das Gesamtüberleben $(p=0,01)$ und das progressionsfreie Überleben $(p<0,01)$ festgestellt wurde. In den molekularen Untergruppen hatten triple-negative Patientinnen mit 2 seltenen Allelen in rs3817198 eine viel bessere Prognose im Hinblick auf ihr Gesamtüberleben (adjustierte HR 0,03; 95\%-KI 0,002-0,279) und ihr progressionsfreies Überleben (HR 0,09; 95\%-KI 0,02-0,36), verglichen mit Patientinnen, welche die häufig vorkommenden Allele aufwiesen. Dieselbe Auswirkung auf das progressionsfreie Überleben fand sich auch bei Patientinnen mit Brustkrebs vom Luminal-A-Typ (HR 0,19; 95\%-KI 0,05-0,84), während Patientinnen mit Brustkrebs vom Typ Luminal-B und 2 seltenen Allelen ein geringeres progressionsfreies Überleben aufwiesen (HR 2,13; 95\%-KI 1,02-4,40). Die Variante in rs3817198 hatte besonders auf die Untergruppe von Patientinnen mit triple-negativem Brustkrebs eine prognostische Auswirkung, was auf eine mögliche Assoziation zwischen Immunmodulation und Brustkrebs hindeutet.

\section{Abbreviations}

$\begin{array}{ll}\text { BCAC } & \text { Breast Cancer Association Consortium } \\ \text { BMI } & \text { Body mass index } \\ \text { BSA } & \text { Body surface area } \\ \text { CI } & \text { Confidence intervals } \\ \text { ER } & \text { Estrogen receptor } \\ \text { FEC } & \text { Fluorouracil, epirubicin and cyclophosphamide } \\ \text { GWAS } & \text { Genome-wide association study } \\ \text { HER2 } & \text { Human epidermal growth factor receptor } 2 \\ \text { HR } & \text { Hazard ratio } \\ \text { OR } & \text { Odds ratio } \\ \text { OS } & \text { Overall survival } \\ \text { PCR } & \text { Polymerase chain reaction } \\ \text { PFS } & \text { Progression-free survival } \\ \text { PR } & \text { Progesterone receptor }\end{array}$

SND Sentinel-node dissection

SNP Single nucleotide polymorphism

\section{Introduction}

Since the publication of the reference genome, several molecular biomarkers have been described for predicting either the prognosis or the drug response in patients with breast cancer. Most of these biomarkers involve gene expression in the tumor and genetic alterations in the tumor and the host [1-4]. Both mutation patterns in the tumor [4] and germline genetic polymorphisms [3, 5] are now being considered for translation into clinical use.

This article focuses on an analysis of confirmed genetic risk factors for breast cancer and their influence on the prognosis in a cohort of breast cancer patients treated with chemotherapy. There is growing evidence that inherited genetic variants can have an 
impact on the prognosis in breast cancer patients. This may be explained by at least two different mechanisms. Firstly, the genetic background in the host may result in variation in drug-response phenotypes involving the metabolism, transportation, and elimination of the drugs used - phenomena investigated in the field known as pharmacogenetics [3,5] - with the variations affecting both the efficacy and the toxicity of a drug. Alternatively, the genetic background of the host might influence the molecular pathogenesis of the developing tumor. Large case-control and casecase studies have shown that inherited single nucleotide polymorphisms (SNPs) can have an influence on both the molecular biology of the tumor and the prognosis of the patient $[1,6-$ $10]$.

The Breast Cancer Association Consortium (BCAC) has identified and validated several SNPs which are associated with breast cancer risk [11-16]. Nine of these eleven SNPs were identified by validating results from genome-wide association studies, and two were identified through gene studies. It has also been noted that rarer susceptibility variants for breast cancer, notably the CHEK2 1100 delC mutation, are associated with poorer survival $[17,18]$.

We have previously shown that some of these genetic polymorphisms are prognostic factors in heterogeneously treated cohorts of breast cancer patients [9]. One of the limitations with studies of large heterogeneously treated cohorts is the limited ability to interpret the results relative to the clinical setting, due to the heterogeneity of the diagnostic methods used for molecular subtypes and the different treatments administered. The aim in the present study was therefore to assess the prognostic effect of these genetic polymorphisms in a larger random subsample from a prospectively randomized breast cancer chemotherapy trial. Analyses were also performed to assess the prognostic effect in commonly accepted molecular subtypes of breast cancer.

\section{Materials and Methods}

\section{Patients and treatment}

The patients included in this analysis were selected from among participants in the SUCCESS A study, an adjuvant phase III randomized open-label trial. Patients were eligible if they had a histologically confirmed invasive breast cancer (pT1-3) with an increased risk for recurrence, defined as being either node-positive, or with a large tumor ( $\geq$ pT2 and grade 3 ) or negative hormonereceptor status. Hormone receptor status was defined positive when $\geq 10 \%$ of cells were positively stained for estrogen and/or progesterone receptor). The multicenter SUCCESS A study was conducted in 251 study centers comprised of academic and nonacademic cancer centers, specialist hospitals, and outpatient clinics in all regions of Germany. The main study and all of the prespecified translational research projects, including the one reported on here, were approved by the ethics committees responsible and informed consent was obtained from all of the individual participants included in the study.

Patients in the SUCCESS A study were treated with three cycles of fluorouracil, epirubicin, and cyclophosphamide (FEC; 500/100/ $500 \mathrm{mg} / \mathrm{m}^{2}$ body surface area, BSA) followed by three cycles of docetaxel (100 mg/m² BSA) every 3 weeks (q3w), vs. three cycles of FEC followed by three cycles of gemcitabine $\left(1000 \mathrm{mg} / \mathrm{m}^{2} \mathrm{BSA}\right.$, d 1,8$)$ and docetaxel $\left(75 \mathrm{mg} / \mathrm{m}^{2} \mathrm{BSA}\right) \mathrm{q} 3 \mathrm{w}$, not reported on here. Following the completion of chemotherapy, the patients were further randomly assigned to receive either two or five years of zoledronic acid treatment. Premenopausal hormone receptor-positive women received tamoxifen alone or in combination with goserelin for 2 years if they were under 40 years of age. Postmenopausal patients were treated with tamoxifen for 2 years, followed by anastrozole for 3 years.

The primary surgery consisted of either breast conservation or mastectomy, leading to R0 resection in all cases. Sentinel-node dissection (SND) was performed in all cN0 patients (with SND as the only axillary intervention), followed by complete axillary node dissection in patients with positive sentinel nodes. The cN1 patients received axillary node dissection primarily. Radiotherapy was performed in accordance with national guidelines $[19,20]$ and was recommended in all patients who received breast-conserving treatment.

\section{Biomaterial sampling and patient selection}

A total of 3754 patients were randomized between September 2005 and March 2007. Whole blood samples were retrieved from 3584 patients at the time point of the randomization. To build a nested case-control study for leukopenia as a toxicity variable (not reported on here), 887 and 888 patients were randomly selected from the group of patients with grade 3 or 4 neutropenia and patients without grade 3 or 4 neutropenia in the first three cycles of the chemotherapy, resulting in a sample size of 1775 patients for genotyping. Eleven patients had to be excluded due to unintended duplication, and 77 patients had to be excluded because less than $98 \%$ of all genotyped SNPs could be called. The final sample size for this study was therefore 1687 . The flow chart for the patient selection process is shown in Fig. S1.

\section{SNP selection}

Nine SNPs associated with a risk for breast cancer were selected that had previously been identified through a genome-wide association study (GWAS) and genotyped in research mainly conducted in the Breast Cancer Association Consortium $(B C A C)>\mathrm{Ta}$ ble 1. Seven of these SNPs were discovered by a GWAS in which BCAC series were used as a replication stage: rs2981582, in intron 2 of FGFR2 (per-allele odds ratio, OR, for breast cancer risk 1.26; $95 \% \mathrm{Cl}, 1.23$ to 1.28 ); rs3803662, a synonymous coding SNP of LOC643 714 that lies $8 \mathrm{~kb}$ upstream of TOX3 (per-allele OR 1.20; $95 \% \mathrm{Cl}, 1.16$ to 1.24 ); rs889312, which lies in a linkage disequilibrium block containing the MAP3K1 gene (per-allele OR 1.13; 95\% $\mathrm{Cl}, 1.10$ to 1.16); rs3817198, which lies in intron 10 of LSP1 (perallele OR 1.07; $95 \% \mathrm{Cl}, 1.04$ to 1.11); rs13281615 at 8q24 (per-allele OR 1.08; $95 \% \mathrm{Cl}, 1.05$ to 1.11) [13]; rs4973768, which is located on the short arm of chromosome 3 near the potentially causative genes SLC4A7 and NEK10 (per-allele OR 1.11; $95 \% \mathrm{Cl}$, 1.08 to $1.13 ; p=4.1 \mathrm{E}-23$ ) [15]; and rs6504950, which lies in intron 1 of STXBP4 (per-allele OR 0.95; $95 \% \mathrm{Cl}, 0.92$ to $0.97 ; \mathrm{p}=1.4$ E-08) [15]. One SNP was identified in a study from Iceland: rs13387042, located in $90 \mathrm{~kb}$ at 2q35, which contains neither known genes nor noncoding RNAs [21] (per-allele OR 1.12; 95\% $\mathrm{Cl}, 1.09$ to $1.15 ; \mathrm{p}=1 \mathrm{E}-19)$ [14]. One validated SNP from candi- 
- Table 1 Description of the nine confirmed breast cancer risk SNPs selected.

\begin{tabular}{|c|c|c|c|c|}
\hline SNP & Local ID & Major allele & Minor allele & Reference \\
\hline rs2981582 & FGFR2/LOC100131885; 10q26 & C & $\mathrm{T}$ & [13] \\
\hline rs3803662 & TNRC9/TOX3/LOC643714; 16q12 & C & $\mathrm{T}$ & [13] \\
\hline rs889312 & MAP3K1/MGC33648/MIER3; 5q11 & A & C & [13] \\
\hline rs3817198 & LSP1/H19; 11p15 & $\mathrm{T}$ & C & [13] \\
\hline rs13281615 & FAM84B/c-MYC; 8q24 & A & G & [13] \\
\hline rs4973768 & SLC4A7/NEK10; 3p24 & C & $\mathrm{T}$ & [15] \\
\hline rs6504950 & STXBP4/COX11/TOM1L1; 17q23 & G & A & [15] \\
\hline rs13387042 & 2q35/TNP1/IGFBP5/IGFBP2/TNS1 & G & A & [14] \\
\hline rs17468277* & CASP8/ALS2CR12; 2q33-q34 & C & $\mathrm{T}$ & {$[12]$} \\
\hline
\end{tabular}

date gene studies was also included [11]: rs1045485, a nonsynonymous change in CASP8 (per-allele OR 0.88; $95 \% \mathrm{Cl}, 0.84$ to 0.92 ; $\mathrm{P}=5.7 \mathrm{E}-07$ ) [12]. Additional SNPs identified by the same group were not taken into consideration in this study [10,22-26].

\section{Genotyping}

Genotyping of these nine SNPs was performed as part of an Illumina GoldenGate custom panel. Genotyping was performed in accordance with the manufacturer's procedures [27]. Genotype data were excluded from analysis in accordance with the following quality control guidelines:

1. any sample that consistently failed for $>2 \%$ of the SNPs;

2. all samples on any one plate that had a call rate $<90 \%$ for any one SNP;

3. all genotype data for any SNP for which the overall call rate was $<95 \%$;

4. all genotype data for any SNP for which duplicate concordance was $<98 \%$.

In addition, for any SNP for which the $\mathrm{p}$ value for departures from Hardy-Weinberg proportions for controls was $<0.005$, clustering of the intensity plots was reviewed manually and the data were excluded if clustering was judged to be poor. On the basis of these criteria, none of the selected SNPs and 77 samples had to be excluded.

\section{Statistical analyses}

Overall survival (OS) was defined as the time from the date of diagnosis to the date of death or date of censoring. Progressionfree survival (PFS) was defined as the time from diagnosis to the date of first progression (distant metastasis, local recurrence, or death) or the date of censoring. Patients who were lost to followup were censored at the last date they were known to be alive and progression-free, respectively.

Survival analyses for OS and PFS, respectively, were performed as described below to investigate the prognostic value of each SNP (homozygous common, heterozygous, homozygous rare), in addition to the well-known prognostic factors age at diagnosis (continuous), body mass index (BMI; continuous), pT (ordinal),
ER (positive vs. negative), PR (positive vs. negative), human epidermal growth factor receptor 2 (HER2; positive vs. negative), grading (ordinal; G1, G2, G3), nodal status (positive vs. negative), and tumor type (ductal, lobular, other). Patients with missing outcome variables were excluded. Missing predictor values were imputed as previously described [28]. Continuous predictors were used as natural cubic spline functions to describe nonlinear effects as done recently [28].

A clinical Cox regression model using the established predictors listed above as main effects, but without any SNP variables, was fitted as the reference model. For each SNP, a Cox model with the SNP and the established predictors as main effects, and the interactions between SNP and ER, PR, HER2, and grading, respectively, as additional effects was fitted to obtain specific results for the molecular subtypes HER2-positive, triple-negative (ER-negative, PR-negative, HER2-negative), luminal A-likes (ER-positive or PR-positive, HER2-negative, grading G1 or G2), luminal B-likes (ER-positive or PR-positive, HER2-negative, grading G3). This genetic Cox model was compared with the clinical Cox model using the likelihood ratio test. The $\mathrm{p}$ values of these tests (one test for each SNP) were corrected using the Bonferroni-Holm method to address the problem of multiple testing. If a corrected $p$ value was significant, then further analyses were carried out. The genetic model was compared with a reduced genetic model in which the interaction terms were dropped, using a likelihood ratio test. A significant result demonstrates different prognostic effects of the SNP between subgroups defined by ER, PR, HER2, and grading. In this case, the interaction model was used to obtain an overall hazard ratio (HR) representing the prognostic effect across all subgroups and to obtain subgroup-specific HRs representing prognostic effects within subgroups. By contrast, a nonsignificant test result indicates that the genetic effect holds equally across all subgroups. In this case, only an overall HR based on the reduced genetic model was shown. All HRs were adjusted for the other predictors taken into account in the model. The proportional hazards assumptions in the SNP models were checked using the Grambsch and Therneau method [29]. Interesting findings were illustrated using Kaplan-Meier curves. 
The performance of the Cox models in terms of discrimination and calibration ("goodness of fit") was measured with the area under the curve (AUC) for survival data [30] and the modified Hosmer-Lemeshow statistic for survival data [31,32]. The AUC ranges from 0.5 (no discrimination at all) to 1 (perfect discrimination at any time point between patients with event already and patients without event then). Following [31], the observed number of events and the model-based estimated number of events within deciles of predicted risk were compared using a goodness of fit $X^{2}$ test. A large $p$ value indicates a satisfactory calibration.

Model building was evaluated by 10 -fold cross-validation with 20 repetitions to address overfitting. For this purpose, the complete model-building process for a SNP was carried out on each training set, resulting in several genetic Cox models (one model per set). The corresponding validation sets were used to calculate AUCs. The average AUC was then taken as an evaluation measure. The smaller the difference between this cross-validated AUC and the original AUC, the lower the amount of overfitting.

A p value of $<0.05$ was regarded as statistically significant. Calculations were carried out using the R system for statistical computing (version 3.0.1; R Development Core Team, Vienna, Austria, 2013).

\section{Results}

A total of 1687 patients were included in the analysis. Twenty-two patients with uncertain HER2 status and one patient for whom there were no survival data had to be excluded. Complete data for patient and tumor characteristics were available for $98.2 \%$ of the patients and complete SNP information for $99.6 \%$ of the patients. The percentage of missing values in each variable was below $1.5 \%$.

The patients' average age was 53.4 ( \pm 10.5$)$. Most of the tumors were staged pT2 and were node-positive ( $n=113 ; 66.9 \%)$. The proportion of patients who had a tumor with a grading of 3 was $45.3 \%(n=754)$. A total of 312 patients $(18.8 \%)$ had triplenegative breast cancer. These characteristics reflect the inclusion criteria used in the study, which focused on high-risk breast cancer patients. Additional patient characteristics are summarized in - Table 2. The median follow-up period was 59 months for overall survival and 58 months for progression-free survival. All of the anticipated prognostic factors showed an influence on overall survival and disease-free survival, as expected (data not shown).

Genotyping showed that all SNPs had minor allele frequencies ranging from 11.7 to $48.8 \%$, showing that the SNPs analyzed were common polymorphisms in the study population ( $\bullet$ Table 3 ). All of the genotype distributions were within the Hardy-Weinberg equilibrium. There were no associations between genotype and tumor characteristics, except for rs2981582 in FGFR2 and hormone receptor status. Patients with the rare genotype showed a higher percentage of hormone receptor-positive tumors. This finding is in agreement with previously published studies.

\section{Overall survival}

The rs3817198 was the only SNP that significantly influenced overall survival (corrected $p=0.01$, likelihood ratio test compar-
- Table 2 Patients' characteristics.

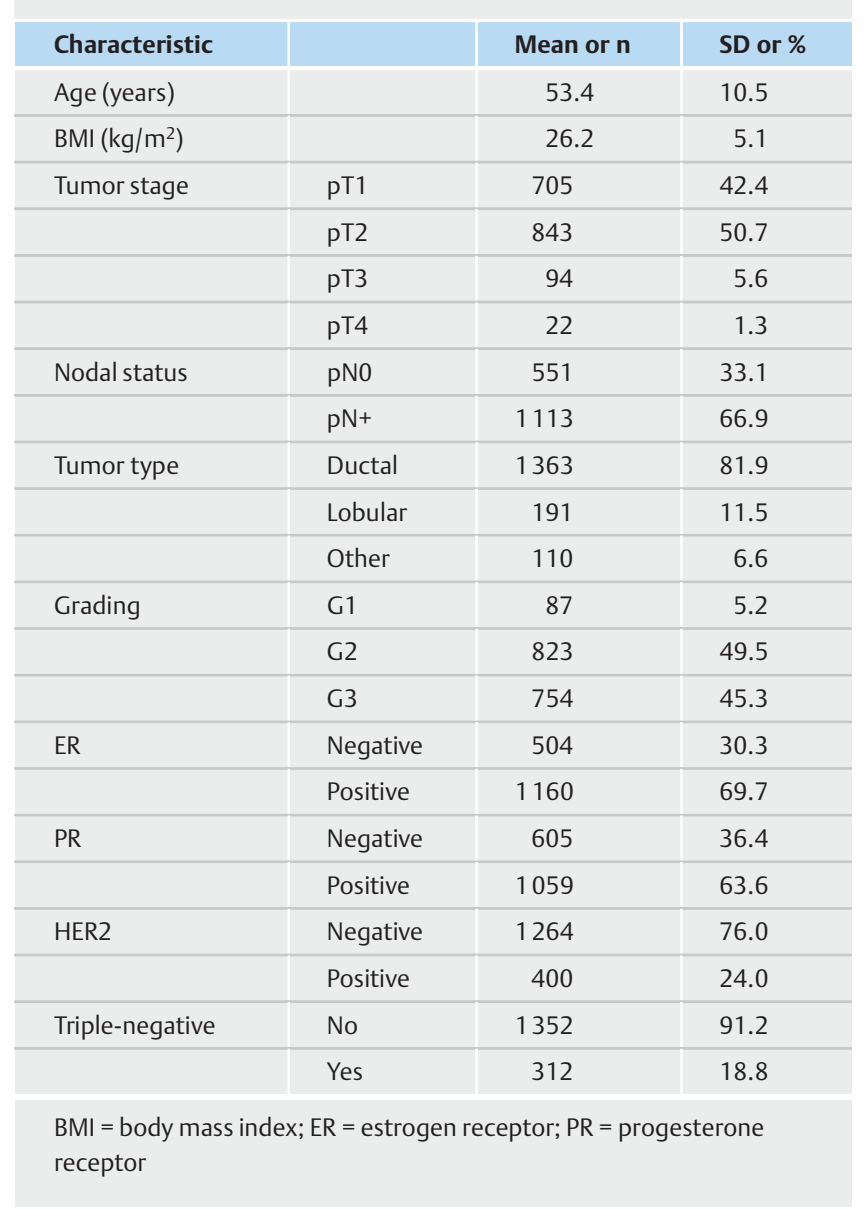

ing the genetic interaction model with the clinical model). All other SNPs considered had non-significant $\mathrm{p}$ values after correction for multiple testing ( $\vee$ Table 3 ). On average - i.e., without looking at specific subgroups - there were no differences between the genotypes with regard to the prognosis ( $\triangleright$ Table 4$)$. There were differences in triple-negative patients. Triple-negative patients with two minor alleles had a longer OS in comparison with patients with common alleles (adjusted HR 0.03; $95 \% \mathrm{Cl}, 0.002$ to 0.279; - Table 4, Fig. 1 a). The genetic regression model used to predict HRs was well calibrated. The difference between observed and predicted events was quite low $(p=0.96$, Hosmer-Lemeshow test). Model discrimination was also good at $A U C=0.794$. The cross-validated AUC was 0.789 , indicating hardly overfitting. For comparison, the observed and the cross-validated AUC of the clinical model was 0.762 and 0.752 , respectively, showing again the additional prognostic value of the genetic model.

\section{Disease-free Survival}

Similar results were seen for progression-free survival. As with the OS, rs3817198 was the only SNP that was associated with PFS (corrected $p<0.001$, likelihood ratio test). Patients with two rare alleles and a triple-negative ( $\vee$ Fig. $\mathbf{1}$ b) or luminal A-like tumor had a better prognosis in comparison with those with triple-nega- 
- Table 3 Genotype and allele distribution, and survival analyses. Absolute frequencies and percentages (in brackets) are shown for each single nucleotide polymorphism (SNP), as well as raw and corrected p values resulting from the comparison between the genetic survival model and the clinical survival model*.

\begin{tabular}{|c|c|c|c|c|c|c|c|c|}
\hline \multirow[t]{2}{*}{ SNP } & \multirow[t]{2}{*}{ MAF (\%) } & \multirow{2}{*}{$\begin{array}{l}\text { Homozygous } \\
\text { common }\end{array}$} & \multirow{2}{*}{$\begin{array}{l}\text { Hetero- } \\
\text { zygous }\end{array}$} & \multirow{2}{*}{$\begin{array}{l}\text { Homozygous } \\
\text { rare }\end{array}$} & \multicolumn{2}{|c|}{ Overall survival } & \multicolumn{2}{|c|}{ Progression-free survival } \\
\hline & & & & & $\begin{array}{l}\text { Raw } \\
\text { P value }\end{array}$ & $\begin{array}{l}\text { Corrected } \\
\text { p value }\end{array}$ & $\begin{array}{l}\text { Raw } \\
\text { p value }\end{array}$ & $\begin{array}{l}\text { Corrected } \\
\text { p value }\end{array}$ \\
\hline rs13281615 & 44.0 & $510(30.6)$ & $844(50.7)$ & $311(18.7)$ & 0.17 & 1.00 & 0.77 & 1.00 \\
\hline rs13387042 & 44.8 & $514(30.9)$ & $810(48.6)$ & $341(20.5)$ & 0.48 & 1.00 & 0.47 & 1.00 \\
\hline rs17468277 & 11.7 & $1306(78.4)$ & $327(19.6)$ & $32(1.9)$ & 0.32 & 1.00 & 0.12 & 0.86 \\
\hline rs2981582 & 42.7 & $532(32.0)$ & $844(50.7)$ & $289(17.4)$ & 0.27 & 1.00 & 0.19 & 1.00 \\
\hline rs3803662 & 31.5 & $796(47.8)$ & $688(41.3)$ & $181(10.9)$ & 0.35 & 1.00 & 0.88 & 1.00 \\
\hline rs3817198 & 32.5 & $747(44.9)$ & $754(45.3)$ & $164(9.8)$ & $<0.01$ & 0.01 & $<0.001$ & $<0.01$ \\
\hline rs4973768 & 48.8 & $444(26.7)$ & $818(49.1)$ & $403(24.2)$ & 0.90 & 1.00 & 0.88 & 1.00 \\
\hline rs6504950 & 26.2 & $896(53.8)$ & $667(40.1)$ & $102(6.1)$ & 0.03 & 0.24 & 0.10 & 0.81 \\
\hline rs889312 & 28.6 & $849(51.0)$ & $681(40.9)$ & $135(8.1)$ & 0.16 & 1.00 & 0.40 & 1.00 \\
\hline
\end{tabular}

- Table 4 Survival analyses relative to SNP rs3817198, showing adjusted* hazard ratios (HRs) with 95\% confidence intervals (Cls) and corresponding $p$ values.

\begin{tabular}{|c|c|c|c|c|c|}
\hline \multirow[t]{2}{*}{ Patients } & \multirow[t]{2}{*}{ Genotype } & \multicolumn{2}{|l|}{ Overall survival } & \multicolumn{2}{|c|}{ Progression-free survival } \\
\hline & & HR $(95 \% \mathrm{Cl})$ & $\mathrm{p}$ value & HR $(95 \% \mathrm{Cl})$ & $\mathrm{p}$ value \\
\hline \multirow[t]{3}{*}{ HER2-positive } & Homozygous common & 1 (reference) & & 1 (reference) & \\
\hline & Heterozygous & $0.70(0.24,2.05)$ & 0.51 & $0.51(0.23,1.11)$ & 0.09 \\
\hline & Homozygous rare & $0.84(0.16,4.43)$ & 0.85 & $0.46(0.13,1.61)$ & 0.22 \\
\hline \multirow[t]{3}{*}{ Triple-negative } & Homozygous common & 1 (reference) & & 1 (reference) & \\
\hline & Heterozygous & $0.71(0.29,1.70)$ & 0.44 & $0.71(0.35,1.44)$ & 0.34 \\
\hline & Homozygous rare & $0.03(0.002,0.279)$ & $<0.01$ & $0.09(0.02,0.36)$ & $<0.001$ \\
\hline \multirow[t]{3}{*}{ Luminal A-like } & Homozygous common & 1 (reference) & & 1 (reference) & \\
\hline & Heterozygous & $0.85(0.36,2.02)$ & 0.71 & $0.73(0.37,1.43)$ & 0.36 \\
\hline & Homozygous rare & $0.24(0.04,1.43)$ & 0.12 & $0.19(0.05,0.84)$ & 0.03 \\
\hline \multirow[t]{3}{*}{ Luminal B-like } & Homozygous common & 1 (reference) & & 1 (reference) & \\
\hline & Heterozygous & $1.38(0.69,2.78)$ & 0.36 & $1.36(0.83,2.23)$ & 0.22 \\
\hline & Homozygous rare & $1.03(0.29,3.73)$ & 0.96 & $2.13(1.02,4.40)$ & 0.04 \\
\hline \multirow[t]{3}{*}{ Overall } & Homozygous common & 1 (reference) & & 1 (reference) & \\
\hline & Heterozygous & $0.80(0.41,1.57)$ & 0.52 & $0.65(0.39,1.10)$ & 0.11 \\
\hline & Homozygous rare & $0.41(0.10,1.69)$ & 0.22 & $0.36(0.13,1.03)$ & 0.06 \\
\hline
\end{tabular}

* HRs for molecular subtypes were adjusted for age, BMI, tumor stage, nodal status, and tumor type. The "overall" HR representing the prognostic effect across the hormone receptor subgroups was adjusted in the same way as the HRs for molecular subtypes and additionally for ER, PR, HER2, and grading. All results are based on the genetic interaction model for overall and progression-free survival. 

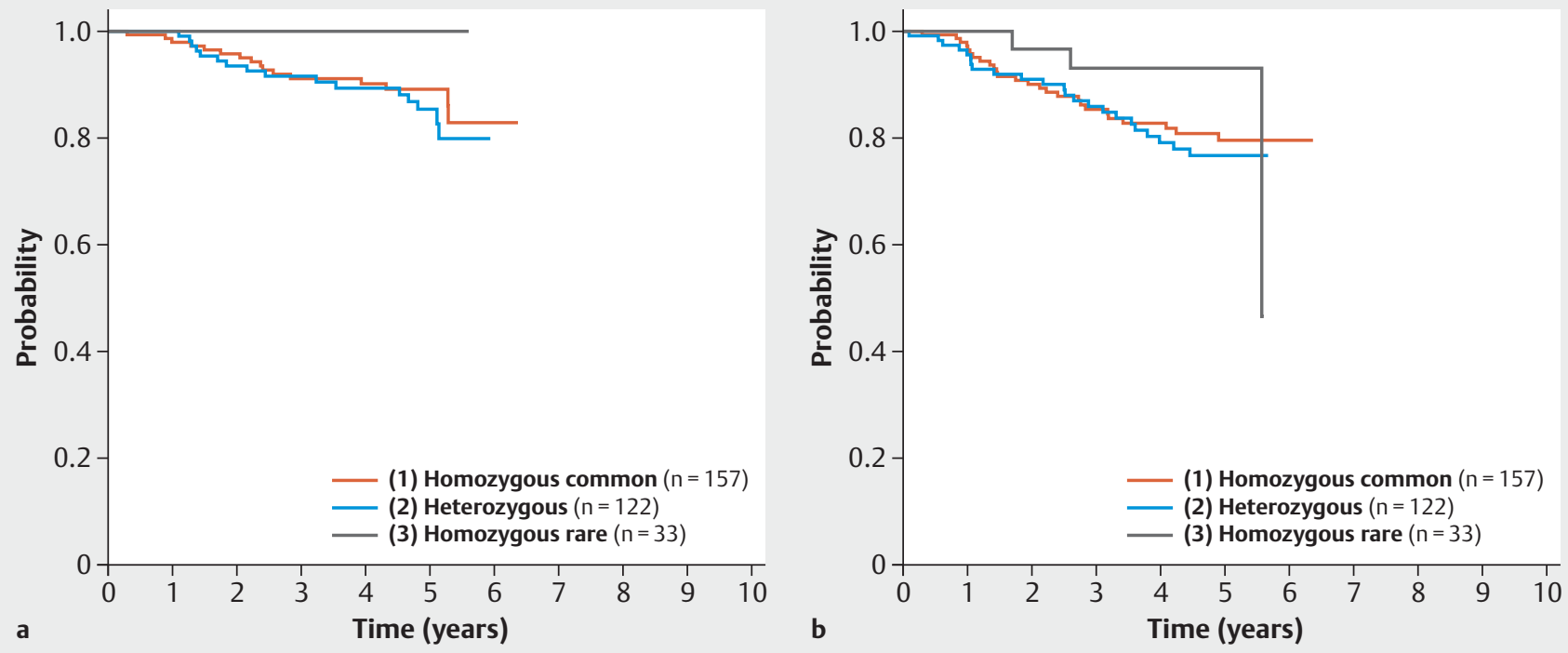

- Fig. 1 Kaplan-Meier curves for SNP rs3817198, showing overall survival (a) and progression-free survival (b) relative to the genotypes in the subgroup of triple-negative patients.

tive or luminal A-like patients with common alleles, with adjusted HRs of 0.09 ( $95 \% \mathrm{Cl}, 0.02$ to 0.36$)$ and $0.19(95 \% \mathrm{Cl}, 0.05$ to 0.84$)$, respectively. The opposite effect was found for patients with luminal B-like tumors. The homozygous rare genotype in these patients was significantly associated with a poorer prognosis with regard to PFS (HR 2.13; $95 \%$ Cl, 1.02 to 4.40; $\triangleright$ Table 4). Again, calibration was satisfactory $(p=0.32)$. The observed and the crossvalidated AUC were 0.726 and 0.718 , the corresponding values for the clinical model were 0.698 and 0.689 .

\section{Discussion}

In a cohort of breast cancer patients treated with anthracyclines and taxanes, this study showed that the SNP rs3817198 in the LSP1 gene has a prognostic effect. This effect was seen in relation to overall survival and progression-free survival in the subgroup of triple-negative patients and only for progression-free survival in luminal A-like breast cancer patients. Specifically, the $C$ allele appeared to have a protective effect with regard to the prognosis in these groups.

Previously, in a large heterogeneously treated cohort analyzed by the BCAC, it was shown that some SNPs associated with a risk of breast cancer have an influence on the prognosis in breast cancer patients. Specifically, SNP rs3803662 in the TOX3 gene was associated with prognosis [9]. In that BCAC study, stratified analyses were carried out for ER-positive and ER-negative patients, which showed some evidence that rs3817198 (LSP1) is a prognostic factor only in ER-negative patients (HR for breast cancer-specific mortality per C allele: $0.71 ; 95 \% \mathrm{Cl}, 0.59$ to 1.00 ) [9]. As only scarce data were available on the patients' HER2 status, an analysis for triple negatives was not possible. In the present study, all biomarkers (ER, PR, and HER2) had to be available at the time of study entry, providing high-quality parameters. In this analysis, the effect of rs3817198 can be attributed to triple-negative and luminal A-like breast cancers only. In another study from the Netherlands, the prognostic relevance of rs3817198 was examined along with other susceptibility loci for breast cancer [33]: rs3817198 was not associated with the prognosis in the low-risk group of 1290 patients with lymph node-negative disease included, who were not treated with chemotherapy.

SNP rs3817198 lies in intron 10 of LSP1 (also known as WP34), encoding lymphocyte-specific protein 1 , a F-actin bundling cytoskeletal protein expressed in hematopoietic and endothelial cells [34-36]. In the Dutch cohort of 1440 patients, the expression of LSP1 in primary breast tumors as assessed by real-time PCR was not associated with the genotype of $r 33817198(p=0.81)$ [33]. In our lymphoblastoid cell lines, there was also no association between gene expression of LSP1 and rs3817198 genotypes (data not shown), making it unlikely that a global change in expression levels is the mode of action for this genetic alteration.

With regard to the association of rs3817198 with patient and tumor characteristics, previous studies have shown inconsistent results for possible correlations with the hormone receptor status. While the previous publication by the BCAC did not find an association [9], a much smaller study claimed an association, although there was no dose-dependent effect relative to the number of alleles [33]. Patients with a TT, TC, or CC genotype were ER-positive in $71,76.2$, and $73.4 \%$ of cases, respectively (calculated from [33]), making an association based on the allele distribution unlikely. On the other hand, the BCAC publication reported an association with HER2 status, with $14.9,14.0$, and $11.9 \%$ being positive for TT, TC, and CC genotypes, respectively.

Interestingly, rs3817198 has been reported to be one of the breast cancer susceptibility loci that is associated with mammographic density $[37,38]$. It is suspected that this effect is medi- 
ated through the regulation of neutrophil motility, adhesion to fibrinogen matrix proteins, and transendothelial migration [38, 39]. Given the fact that $L S P 1$ expression in endothelial cells is crucial for neutrophil transendothelial migration [35], the prognostic phenotype observed might be of a complex nature.

The present study has both strengths and limitations. Although pharmacogenetic analyses were specified in advance in the study protocol, the analysis was retrospective in nature. The analyses were also conducted in a subset of patients who were randomly selected in order to construct a case-control study for the presence of neutropenia/leukopenia. The reason for the nested case-control study design was the need to reduce genotyping costs. However, when the selected patients were compared with the unselected patients, no differences were found with regard to the common prognostic factors listed in $>$ Table 1 (data for comparison not shown). Nevertheless, the possibility cannot be excluded that there are interactions between the occurrence of leukopenia and the prognosis, possibly resulting in a bias that does not emerge when the possible confounders in $>\mathbf{T a}$ ble 1 are compared.

The study shows that the breast cancer susceptibility SNP rs3817198 in LSP1 has prognostic relevance in a group of patients treated with anthracycline and taxane chemotherapy. Another susceptibility SNP (rs3803662 in TOX3), which has previously been described as being of prognostic relevance in a heterogeneously treated group of patients, was not confirmed in the SUCCESS A study. On the basis of the results of this study, the hypotheses can therefore be formulated that rs3817198 in LSP1 may act as a pharmacogenetic marker predicting the prognostic effect through responsiveness to chemotherapy, and that rs3803662 in TOX3 acts as a prognostic factor through other mechanisms. However, this will need to be confirmed in studies in which these patient groups can be directly compared with each other.

\section{Acknowledgment}

The authors are grateful to Sonja Oeser and Silke Landrith for management of samples and biomaterials. The authors are also grateful to Michael Robertson for professional medical editing services.

\section{Funding}

This work was supported by institutional funding. Mayo Clinic grant CA15083 supported the genotyping activities in the Mayo Clinic Genotyping Core Facility. The conduction of the main clinical phase III study was supported by grants from Novartis, AstraZeneca, Chugai, Sanofi-Aventis Deutschland GmbH, and Lilly.

\section{Conflict of Interest}

Peter Fasching has received honoraria from Genomic Health, Teva, Novartis, Amgen, Pfizer and Roche, and he has conducted research for Novartis and Amgen. Brigitte Rack has received research funding from Chugai, Sanofi-Aventis Deutschland $\mathrm{GmbH}$, Lilly, Novartis and AstraZeneca. All other authors have declared no conflict of interest.

\section{References}

[1] Curtis C, Shah SP, Chin SF et al. The genomic and transcriptomic architecture of 2,000 breast tumours reveals novel subgroups. Nature 2012; 486: 346-352

[2] Sotiriou C, Pusztai L. Gene-expression signatures in breast cancer. N Engl J Med 2009; 360: 790-800

[3] Wang L, McLeod HL, Weinshilboum RM. Genomics and drug response. N Engl J Med 2011; 364: 1144-1153

[4] Cancer Genome Atlas Network. Comprehensive molecular portraits of human breast tumours. Nature 2012; 490: 61-70

[5] Weinshilboum RM, Wang L. Pharmacogenetics and pharmacogenomics: development, science, and translation. Annu Rev Genomics Hum Genet 2006; 7: 223-245

[6] Garcia-Closas M, Hall P, Nevanlinna H et al. Heterogeneity of breast cancer associations with five susceptibility loci by clinical and pathological characteristics. PLoS Genet 2008; 4: e1000054

[7] Broeks A, Schmidt MK, Sherman ME et al. Low penetrance breast cancer susceptibility loci are associated with specific breast tumor subtypes: Findings from the Breast Cancer Association Consortium. Hum Mol Genet 2011; 20: 3289-3303

[8] Reeves GK, Travis RC, Green J et al. Incidence of breast cancer and its subtypes in relation to individual and multiple low-penetrance genetic susceptibility loci. JAMA 2010; 304: 426-434

[9] Fasching PA, Pharoah PD, Cox A et al. The role of genetic breast cancer susceptibility variants as prognostic factors. Hum Mol Genet 2012; 21: 3926-3939

[10] Garcia-Closas M, Couch F], Lindstrom S et al. Genome-wide association studies identify four ER negative-specific breast cancer risk loci. Nat Genet 2013; 45: 392-398

[11] Breast Cancer Association Consortium. Commonly studied single-nucleotide polymorphisms and breast cancer: results from the Breast Cancer Association Consortium. J Natl Cancer Inst 2006; 98: 1382-1396

[12] Cox A, Dunning AM, Garcia-Closas M et al. A common coding variant in CASP8 is associated with breast cancer risk. Nat Genet 2007; 39: 352358

[13] Easton DF, Pooley KA, Dunning AM et al. Genome-wide association study identifies novel breast cancer susceptibility loci. Nature 2007; 447: 1087-1093

[14] Milne RL, Benítez J, Nevanlinna H et al. Risk of estrogen receptor-positive and -negative breast cancer and single-nucleotide polymorphism 2q35rs13387042. J Natl Cancer Inst 2009; 101: 1012-1018

[15] Ahmed S, Thomas G, Ghoussaini M et al. Newly discovered breast cancer susceptibility loci on 3p24 and 17q23.2. Nat Genet 2009; 41: 585-590

[16] Stacey SN, Manolescu A, Sulem P et al. Common variants on chromosome $5 \mathrm{p} 12$ confer susceptibility to estrogen receptor-positive breast cancer. Nat Genet 2008; 40: 703-706

[17] CHEK2 Breast Cancer Case-Control Consortium. CHEK2*1100delC and susceptibility to breast cancer: a collaborative analysis involving 10,860 breast cancer cases and 9,065 controls from 10 studies. Am J Hum Genet 2004; 74: 1175-1182

[18] Schmidt MK, Tollenaar RA, de Kemp SR et al. Breast cancer survival and tumor characteristics in premenopausal women carrying the CHEK2*1100delC germline mutation. J Clin Oncol 2007; 25: 64-69

[19] Sautter-Bihl ML, Budach W, Dunst J et al. DEGRO practical guidelines for radiotherapy of breast cancer I: breast-conserving therapy. Strahlenther Onkol 2007; 183: 661-666

[20] Sautter-Bihl ML, Souchon R, Budach W et al. DEGRO practical guidelines for radiotherapy of breast cancer II. Postmastectomy radiotherapy, irradiation of regional lymphatics, and treatment of locally advanced disease. Strahlenther Onkol 2008; 184: 347-353 
[21] Stacey SN, Manolescu A, Sulem P et al. Common variants on chromosomes 2 q35 and $16 q 12$ confer susceptibility to estrogen receptor-positive breast cancer. Nat Genet 2007; 39: 865-869

[22] Antoniou AC, Wang X, Fredericksen ZS et al. A locus on 19p13 modifies risk of breast cancer in BRCA1 mutation carriers and is associated with hormone receptor-negative breast cancer in the general population. Nat Genet 2010; 42: 885-892

[23] Haiman CA, Chen GK, Vachon CM et al. A common variant at the TERTCLPTM1 L locus is associated with estrogen receptor-negative breast cancer. Nat Genet 2011; 43: 1210-1214

[24] Ghoussaini M, Fletcher O, Michailidou K et al. Genome-wide association analysis identifies three new breast cancer susceptibility loci. Nat Genet 2012; 44: 312-318

[25] Bojesen SE, Pooley KA, Johnatty SE et al. Multiple independent variants at the TERT locus are associated with telomere length and risks of breast and ovarian cancer. Nat Genet 2013; 45: 371-384

[26] Michailidou K, Hall P, Gonzalez-Neira A et al. Large-scale genotyping identifies 41 new loci associated with breast cancer risk. Nat Genet 2013; 45: 353-361

[27] Oliphant A, Barker DL, Stuelpnagel JR et al. BeadArray technology: enabling an accurate, cost-effective approach to high-throughput genotyping. Biotechniques 2002; (Suppl.): 56-58, 60-61

[28] Salmen J, Neugebauer J, Fasching PA et al. Pooled analysis of the prognostic relevance of progesterone receptor status in five German cohort studies. Breast Cancer Res Treat 2014; 148: 143-151

[29] Grambsch PM, Therneau TM. Proportional hazards tests and diagnostics based on weighted residuals. Biometrika 1994; 81: 515-526

[30] Chambless LE, Diao G. Estimation of time-dependent area under the ROC curve for long-term risk prediction. Stat Med 2006; 25: 3474-3486
[31] Gronnesby JK, Borgan O. A method for checking regression models in survival analysis based on the risk score. Lifetime Data Anal 1996; 2: 315-328

[32] May S, Hosmer DW. A simplified method of calculating an overall goodness-of-fit test for the cox proportional hazards model. Lifetime Data Anal 1998; 4: 109-120

[33] Riaz M, Berns EM, Sieuwerts AM et al. Correlation of breast cancer susceptibility loci with patient characteristics, metastasis-free survival, and mRNA expression of the nearest genes. Breast Cancer Res Treat 2012; 133: $843-851$

[34] Petri B, Kaur J, Long EM et al. Endothelial LSP1 is involved in endothelial dome formation, minimizing vascular permeability changes during neutrophil transmigration in vivo. Blood 2011; 117: 942-952

[35] Liu L, Cara DC, Kaur J et al. LSP1 is an endothelial gatekeeper of leukocyte transendothelial migration. J Exp Med 2005; 201: 409-418

[36] Jongstra-Bilen J, Jongstra J. Leukocyte-specific protein 1 (LSP1): a regulator of leukocyte emigration in inflammation. Immunol Res 2006; 35: 65-74

[37] Tamimi RM, Cox D, Kraft P et al. Breast cancer susceptibility loci and mammographic density. Breast Cancer Res 2008; 10: R66

[38] Vachon CM, Scott CG, Fasching PA et al. Common breast cancer susceptibility variants in LSP1 and RAD51L1 are associated with mammographic density measures that predict breast cancer risk. Cancer Epidemiol Biomarkers Prev 2012; 21: 1156-1166

[39] Lanigan F, O'Connor D, Martin F et al. Molecular links between mammary gland development and breast cancer. Cell Mol Life Sci 2007; 64: 3159-3184 